\title{
Nível de Concentrado, Variedade da Silagem de Sorgo e Grupo Genético sobre a Qualidade da Carcaça e da Carne de Novilhos Confinados
}

\section{Fabiano Nunes Vaz1, João Restle², Nilton Luiz Queiroz Silva ${ }^{3}$, Dari Celestino Alves Filho, Leonir Luiz Pascoal ${ }^{5}$, Ivan Luiz Brondani ${ }^{6}$, Fernando Kuss ${ }^{7}$}

\begin{abstract}
RESUMO - O efeito de dietas com três níveis de concentrado, associados à silagem de dois híbridos de sorgo, sobre a qualidade da carcaça e da carne de novilhos foi avaliado, utilizando-se 60 animais mestiços com predominância de Charolês ou de Nelore, terminados em confinamento dos 20 aos 22 meses de idade. Os novilhos apresentavam $322 \mathrm{~kg}$ de peso inicial e foram distribuídos em delineamento inteiramente casualizado em um esquema fatorial 3 x 2 x 2, ou seja, três níveis de concentrado (25, 35 e $45 \%$ da matéria seca da dieta), dois tipos de silagem de sorgo (forrageiro e duplo propósito) e dois grupos genéticos. A interação foi significativa entre tipo de silagem e genótipo somente para a característica quebra ao descongelamento. Animais alimentados com silagem de sorgo forrageiro apresentaram carne de melhor palatabilidade $(6,37 \pm 0,14$ vs $5,74 \pm 0,14$ pontos $)$, menor perda durante a cocção $(26,7 \pm 0,8$ vs $29,2 \pm 0,8 \%)$ e de pior coloração $(3,49 \pm 0,15$ vs 4,00 $\pm 0,15$ pontos $)$ que aqueles alimentados com silagem de sorgo duplo propósito. A maciez da carne melhorou à medida que aumentou o nível de concentrado na dieta, com 5,40 $\pm 0,16 ; 5,71 \pm 0,26$ e 6,42_ $\pm 0,23$ pontos, respectivamente, para 25, 35 e 45\%. O mesmo foi verificado para a conformação de carcaça, com 9,7 $\pm 0,4 ; 9,8 \pm 0,3$ e 10,8 \pm , 4 pontos, citados na mesma ordem. Entre os genótipos, observou-se que novilhos mestiços com predominância de Charolês apresentaram melhor conformação de carcaça (10,8 \pm 0,3 vs $9,4 \pm \pm 0,3$ pontos) e carne mais macia ( $6,43 \pm 0,18$ vs $5,26 \pm 0,21$ pontos), mais suculenta ( $5,99 \pm 0,11$ vs $5,60 \pm 0,13$ pontos), com menor perda ao descongelamento $(6,40 \pm 0,51$ vs $8,69 \pm 0,58 \%)$ e maior grau de marmoreio $(4,76 \pm 0,30$ vs $3,77 \pm 0,34$ pontos $)$, enquanto os mestiços com predominância de Nelore apresentaram maior porcentagem de gordura na carcaça $(22,3 \pm 0,6$ vs $18,9 \pm 0,5 \%)$.
\end{abstract}

Palavras-chave: Bos taurus indicus, Bos taurus taurus, características da carcaça, características da carne, maciez da carne, marmoreio

\section{Concentrate Level, Sorghum Silage Variety and Genetic Group on Carcass and Meat Quality of Confined Steers}

\begin{abstract}
This work was conducted with the objective to study three concentrate levels in the diet in combination with silage of two sorghum silage hybrids, on the carcass and meat quality of crossbred steers with Charolais or Nellore predominance. Sixty animals were finished in feedlot from 20 to 22 months, with $322 \mathrm{~kg}$ of initial weight, and were allotted to completely randomized design 3 x 2 x 2 factorial scheme, according to three concentrate levels $(25,35$ and $45 \%$ of the diet dry matter), silage of two sorghum silage hybrids (forage and double purpose sorghum) and two genetic groups. The interaction was significant between sorghum hybrid and genotype for thawing loss characteristic. Steers fed double purpose sorghum silage showed meat with better flavor (6.37 \pm 0.14 vs $5.74 \pm 0.14$ points), lower cooking loss $(26.7 \pm 0.8$ vs $29.2 \pm 0.8 \%)$ and meat of worse coloration (3.49 \pm .15 vs $4.00 \pm .15$ points) than those fed with double purpose silage. Meat tenderness increased with the increase of diet concentrate level, being $5.40 \pm .16,5.71 \pm .26$ and $6.42 \pm .23$ points, respectively, for 25,35 and $45 \%$, the same was verified for carcass conformation, $9.7 \pm .4,9.8 \pm .3$ and $10.8 \pm .4$, written in the same order. Between genotypes, Charolais crossbred steers displayed better carcass conformation (10.8 \pm .3 vs $9.4 \pm .3$ points) and more tender meat $(6.43 \pm .18$ vs $5.26 \pm .21$ points), juicier (5.99 \pm .11 vs $5.60 \pm .13$ points), with lower thawing loss $(6.40 \pm .51$ vs $8.69 \pm .58 \%)$ and with higher marbling score $(4.76 \pm .30$ vs $3.77 \pm .34$ points), while Nellore crossbred steers showed higher carcass fat percentage (22.3 \pm .6 vs $18.9 \pm .5 \%)$.
\end{abstract}

Key Words: Bos taurus indicus, Bos taurus taurus, carcass characteristics, marbling, meat characteristics, meat tenderness

\section{Introdução}

Segundo Restle \& Vaz (2002) a produção de bovinos de corte brasileira pode ser potencializada com o aumento do consumo interno de carne bovina e das exportações, que somam pouco mais de $10 \%$ da produção nacional. Entretanto, de acordo com esses autores, é preciso estabelecer padrões de qualidade na carne bovina, com o intuito de fidelizar consumidores e reconquistar o espaço do consumo per capita

\footnotetext{
1 Zootecnista, MS, Doutorando Programa Pós-Graduação em Agronegócios CEPAN - UFRGS, Bolsista do CNPq. Endereço: Rua Benjamin Constant, 930/313, Santa Maria - RS, CEP: 97050-020. E.mail: fnvaz@terra.com.br

2 Engenheiro Agrônomo, PhD, Pesquisador Visitante UFG, Bolsista CNPq. E.mail: jorestle@terra.com.br

3 Zootecnista, MS, Doutorando Programa Pós-Graduação em Zootecnia - UFRGS, Bolsista CNPq. E.mail: gatora@terra.com.br

${ }^{4}$ Engenheiro Agrônomo, MS, Doutorando Programa Pós-Graduação em Zootecnia - UFRGS, Professor Assistente do Departamento de Zootecnia - UFSM. E.mail: dcafilho@ccr.ufsm.br

${ }^{5}$ Zootecnista, MS, Doutorando Programa Pós-Graduação em Zootecnia - UFRGS, Professor Assistente do Departamento de Zootecnia - UFSM. E.mail: pascoal@ccr.ufsm.br

6 Zootecnista, Dr., Professor Adjunto do Departamento de Zootecnia - UFSM.

7 Zootecnista, MS, Doutorando Programa Pós-Graduação em Zootecnia - UFRGS.
} 
perdido ao longo dos anos para produtos com maior constância de qualidade, ressaltando-se a importância da terminação de animais com idade jovem, que pode ser alcançada com bons níveis alimentares, resultando em carne com poucas variações qualitativas, sobretudo maciez.

Nos últimos anos, as pesquisas em produção animal têm apontado várias alternativas para a terminação dos animais em idade jovem, entre elas, o confinamento, com grande adoção entre os produtores, que passaram a usar esta tecnologia a partir do grande volume de informações produzidas nas universidades e institutos de pesquisa brasileiros acerca da composição da dieta a ser usada (Restle \& Vaz, 2003).

Nessa linha de pesquisa, Vaz et al. (2002) verificaram que o nível de concentrado utilizado como suplemento para vacas de descarte mestiças Charolês $\mathrm{x}$ Nelore, em pastejo sobre Lolium multiflorum + Avena strigosa, não afetou as características cor, textura e marmoreio da carne, composição física da carcaça, características sensoriais da carne e quebras ao descongelamento e à cocção.

Para a terminação em confinamento, a silagem de sorgo vem despertando a preferência dos produtores, por apresentar alta produtividade da lavoura e menor sensibilidade a períodos curtos de estiagem, fazendo com que as pesquisas desenvolvam novos híbridos mais adaptados e produtivos, tornando a escolha do híbrido a ser cultivado e ensilado de fundamental importância para o produtor, que deve oferecer qualidade associada à alta produtividade (Neumann et al., 2002).

Com relação ao genótipo bovino a ser usado, alguns pesquisadores têm observado que, na comparação entre animais de raças continentais e mestiços Nelore, os primeiros apresentam maior musculosidade na carcaça em detrimento à deposição de gordura, que é maior na carcaça dos Nelore (Perobelli et al., 1994; Vaz, 1999). Entretanto, Moletta \& Restle (1996) comprovam que o nível energético da dieta pode propiciar que novilhos Charolês, ou mestiços com predominância deste genótipo, atinjam condições de abate em idade reduzida e grau de acabamento semelhante ao de genótipos com predominância de Nelore.

O experimento foi conduzido com o objetivo de avaliar diferentes dietas, compostas por três níveis de concentrado, associados à silagem de dois híbridos de sorgo, sobre as características de carcaça de novilhos com predominância de Nelore ou Charolês.

\section{Material e Métodos}

O experimento foi conduzido nas dependências do Setor de Bovinocultura de Corte e as análises da carne foram realizadas no Laboratório de Carnes, ambos pertencentes ao Departamento de Zootecnia da Universidade Federal de Santa Maria, RS, no período de junho a agosto. Foram confinados 60 novilhos com idade inicial de 20 meses e peso inicial de $322 \mathrm{~kg}$, distribuídos ao acaso em esquema fatorial $3 \times 2 \times 2$ (três níveis de concentrado, dois tipos de silagem de sorgo e dois grupos genéticos).

Os tratamentos constaram da combinação de dois híbridos de sorgo, forrageiro (FO) ou duplo propósito (DP), com três níveis de concentrado 25; 35 e 45\% (na base da matéria seca da dieta) oferecidos a novilhos com genótipo predominante Charolês (C) ou Nelore $(\mathrm{N})$, obtendo-se doze tratamentos: FO25C, FO25N, FO35C, FO35N, FO45C, FO45N, DP25C, DP25N, DP35C, DP35N, DP45C e DP45N.

O grupo de novilhos com predominância de Charolês foi formado por animais Charolês definidos, 3/4 Charolês $+1 / 4$ Nelore e 5/8 Charolês $+3 / 8$ Nelore, enquanto o grupo de novilhos com predominância de Nelore foi formado por animais Nelore definidos e 3/4 Nelore + 1/4 Charolês, todos nascidos na mesma época de parição, oriundos do mesmo rebanho experimental e tratados sempre sob as mesmas condições de alimentação, sanidade e manejo.

Os concentrados utilizados nos diferentes níveis foram balanceados, utilizando-se sorgo em grão, farelo de soja e minerais, de acordo com o volumoso ao qual foram associados, de modo que as dietas oferecessem $12 \%$ de proteína bruta (Tabela 1 ).

Os animais foram distribuídos em doze lotes de cinco animais - cada lote foi alojado em piquete parcialmente coberto, com área total de $40 \mathrm{~m}^{2}$-, providos de cocho e bebedouro regulado por torneirabóia. A ração diária foi fracionada em duas partes e oferecida pela manhã e pela tarde, deixando os animais com alimento disponível 24 horas por dia. Pela manhã, as sobras do dia anterior eram recolhidas e pesadas. A Tabela 2 apresenta a composição dos ingredientes utilizados nas dietas balanceadas.

$\mathrm{O}$ abate dos animais ocorreu conforme o fluxo normal do frigorífico. As carcaças foram identificadas, divididas em duas metades, lavadas e levadas ao resfriamento por 24 horas a uma temperatura de $-2^{\circ} \mathrm{C}$. Após esse tempo, as carcaças tiveram sua conformação avaliada subjetivamente, a partir de uma escala de 1 a 18 pontos, conforme metodologia proposta por Müller(1987). 
Tabela 1 - Composição média do concentrado (em porcentagem da MS), de acordo com o nível utilizado

Table 1 - Concentrate average composition (in DM percentage), according to the used level

\begin{tabular}{lccc}
\hline $\begin{array}{l}\text { Ingrediente } \\
\text { Ingredient }\end{array}$ & \multicolumn{3}{c}{$\begin{array}{c}\text { Nível de concentrado, } \\
\text { Concentrate level, \% }\end{array}$} \\
\cline { 2 - 4 } & 25 & 35 & 45 \\
\hline $\begin{array}{l}\text { Sorgo grão triturado } \\
\text { Grounded sorghum grain }\end{array}$ & 83,4 & 89,0 & 91,6 \\
$\begin{array}{l}\text { Farelo de soja } \\
\text { Soybean meal }\end{array}$ & 8,9 & 4,3 & 2,4 \\
Uréia & 3,3 & 2,4 & 1,8 \\
$\begin{array}{l}\text { Urea } \\
\text { Sulfato de amônia } \\
\text { Amonium sulphate }\end{array}$ & 0,4 & 0,3 & 0,2 \\
$\begin{array}{l}\text { Calcário calcítico } \\
\text { Limestone }\end{array}$ & 3,0 & 3,0 & 3,0 \\
$\begin{array}{l}\text { Sal comum } \\
\text { Salt }\end{array}$ & 1,0 & 1,0 & 1,0 \\
\hline
\end{tabular}

Tabela 2 - Composição dos ingredientes das dietas experimentais

Table 2 - Composition of the ingredients used in the experimental diets

\begin{tabular}{|c|c|c|c|c|}
\hline & $\begin{array}{c}\text { Silagem } \\
\text { de sorgo } \\
\text { forrageiro } \\
\text { Forage sorghum } \\
\text { silage }\end{array}$ & $\begin{array}{c}\text { Silagem } \\
\text { de sorgo } \\
\text { duplo propósito } \\
\text { Double purpose } \\
\text { sorghum silage }\end{array}$ & $\begin{array}{l}\text { Grão de } \\
\text { sorgo } \\
\text { Sorghum } \\
\text { grain }\end{array}$ & $\begin{array}{l}\text { Farelo de } \\
\text { soja } \\
\text { Soybean } \\
\text { meal }\end{array}$ \\
\hline $\begin{array}{l}\text { Matéria seca (MS), \% } \\
\text { Dry matter }(D M), \% \\
\% \text { da MS } \\
\% \text { of } D M\end{array}$ & 30,2 & 33,4 & 88,0 & 87,9 \\
\hline $\begin{array}{l}\text { Proteína bruta } \\
\text { Crude protein }\end{array}$ & 6,43 & 7,22 & 9,19 & 44,01 \\
\hline $\begin{array}{l}\text { Matéria mineral } \\
\text { Mineral matter }\end{array}$ & 3,07 & 4,15 & 0,81 & 5,27 \\
\hline $\begin{array}{l}\text { Fibra em detergente neutro } \\
\text { Neutral detergent fiber }\end{array}$ & 57,2 & 52,5 & 16,1 & 14,9 \\
\hline $\begin{array}{l}\text { Fibra em detergente ácido } \\
\text { Acid detergent fiber }\end{array}$ & 33,1 & 28,9 & 6,4 & 10,0 \\
\hline $\begin{array}{l}\text { Digestibilidade in vitro da } \mathrm{MS} \\
\text { In vitro DM digestibility }\end{array}$ & 57,8 & 70,2 & 81,8 & 84,6 \\
\hline $\begin{array}{l}\text { D. in vitro da matéria orgânica } \\
\text { In vitro organic matter digestibility }\end{array}$ & 59,0 & 70,8 & 82,3 & 82,7 \\
\hline $\begin{array}{l}\text { Energia digestível, } \mathrm{Mcal} / \mathrm{kg} \\
\text { Digestible energy, Mcal/kg }\end{array}$ & 2,60 & 3,08 & 3,70 & 3,56 \\
\hline
\end{tabular}

Seqüencialmente, realizou-se o corte da carcaça esquerda na altura da 12 $\underline{\text { a }}$ costela e, após a exposição do músculo Longissimus dorsi por 20 minutos, para oxigenação da mioglobina, avaliaram-se as características cor e textura (em escala de cinco pontos) e marmoreio da carne, classificado em uma escala de dezoito pontos (Müller, 1987). Após essas medidas, foi retirada da meia-carcaça direita uma secção da 9-11 a costela e do lombo, para determinação da composição física da carcaça, conforme as equações sugeridas por Hankins \& Howe (1946).
A porção do músculo Longissimus dorsi removida dessa amostra foi imediatamente embalada, identificada e congelada. Posteriormente, a partir do músculo congelado, foram extraídas duas fatias (A e B) de $2,5 \mathrm{~cm}$ de espessura, obtidas perpendicularmente ao comprimento do músculo, que foram usadas para avaliação das características sensoriais (fatia A) e da quebra ao descongelamento, quebra à cocção e resistência das fibras ao corte (fatia B).

Para o cálculo das perdas ao descongelamento e cocção, realizou-se a pesagem da fatia B, ainda con- 
gelada, depois de descongelada (antes de ser levada ao forno) e após o cozimento, que aconteceu até que a temperatura interna da fatia atingisse $70^{\circ} \mathrm{C}$. A pesagem da fatia cozida foi realizada em aparelho Warner-Bratzler Shear, após voltar à temperatura ambiente, retirando-se três amostras de feixes de fibras, circulares, com $1 \mathrm{~cm}^{2}$, cortadas perpendicularmente à fibra. Para se obter a medida, calculou-se a média aritmética de seis leituras (duas por amostra).

As características sensoriais da carne foram avaliadas após a cocção das fatias de músculo, distribuindo-se uma porção de $1 \mathrm{~cm}^{3}$ da fatia A para cada um dos avaliadores, previamente treinados, que atribuíram valores de 1 a 9 para as características maciez, suculência e palatabilidade da carne, em uma escala em que os valores aumentam conforme melhoram os atributos da carne (Müller, 1987).

O delineamento experimental foi inteiramente casualizado em um arranjo fatorial $3 \times 2 \times 2$. Os dados foram analisados utilizando-se o seguinte modelo estatístico:

$$
\begin{aligned}
& \mathrm{Y}_{\mathrm{ijkl}}=\mathrm{m}+\mathrm{NC}_{\mathrm{i}}+\mathrm{TS}_{\mathrm{j}}+\mathrm{GG}_{\mathrm{k}}+\mathrm{NC}_{\mathrm{i}} * \mathrm{TS}_{\mathrm{j}}+ \\
& \mathrm{NC}_{\mathrm{i}}{ }^{*} \mathrm{GG}_{\mathrm{k}}+\mathrm{TS}_{\mathrm{j}}{ }^{*} \mathrm{GG}_{\mathrm{k}}+\mathrm{NC}_{\mathrm{i}} * \mathrm{TS}_{\mathrm{j}} * \mathrm{GG}_{\mathrm{k}}+\mathrm{e}_{\mathrm{ijkl}} \text {, }
\end{aligned}
$$

em que $Y_{i j k l}$ representa a observação no l-ésimo animal, pertencente ao i-ésimo nível de concentrado, j-ésimo tipo de silagem e ao k-ésimo grupo genético; $\mathrm{m}$, a média geral da característica; $\mathrm{NC}_{\mathrm{i}}$, o i-ésimo nível de concentrado; $\mathrm{TS}_{\mathrm{j}}$, o j-ésimo tipo de silagem; $\mathrm{GG}_{\mathrm{k}}$, o k-ésimo grupo genético; $\mathrm{e}_{\mathrm{ijkl}}$, o efeito residual.

As interações foram analisadas para cada variável e aquelas não-significativas foram removidas do modelo final. Os tratamentos que apresentaram efeito significativo sobre as variáveis foram comparados pelo teste t a 5\% de significância.

\section{Resultados e Discussão}

A única interação significativa $(\mathrm{P}<0,05)$ ocorreu entre tipo de silagem e genótipo para a característica quebra da carne ao descongelamento. Portanto, os resultados passam a ser discutidos em função dos efeitos de tipo de silagem, nível de concentrado e genótipo.

$\mathrm{Na}$ Tabela 3 constam os resultados referentes às características conformação e composição física da carcaça dos novilhos.

A conformação foi melhor nos animais alimentados com $45 \%$ de concentrado ( 10,79 pontos) que nos novilhos que consumiram $25 \%$ de concentrado $(9,67$ pontos). Usando vacas mestiças Charolês x Nelore, Vaz et al. (2002) observaram leve aumento na confor-

Tabela 3 - Médias e desvios-padrão para características da carcaça de novilhos alimentados com diferentes níveis de concentrado

Table 3 - Means and standard deviations for carcass characteristicas of steers fed different

\begin{tabular}{|c|c|c|c|c|}
\hline \multirow[t]{2}{*}{$\begin{array}{l}\text { Características } \\
\text { Characteristics }\end{array}$} & \multicolumn{3}{|c|}{$\begin{array}{l}\text { Nível de concentrado, \% } \\
\text { Concentrate level, \% }\end{array}$} & \multirow[t]{2}{*}{$\begin{array}{l}\text { Probabilidade } \\
\text { Probability }\end{array}$} \\
\hline & 25 & 35 & 45 & \\
\hline $\begin{array}{l}\text { Conformação, pontos }{ }^{1} \\
\text { Conformation, points }{ }^{1}\end{array}$ & $9,67 \pm 0,39 b^{2}$ & $9,77 \pm 0,34 \mathrm{ab}$ & $10,79 \pm 0,35 \mathrm{a}$ & 0,0403 \\
\hline $\begin{array}{l}\text { Porcentagem de músculo } \\
\text { Muscle percentage }\end{array}$ & $64,1 \pm 0,6$ & $63,8 \pm 0,5$ & $63,6 \pm 0,6$ & 0,8077 \\
\hline $\begin{array}{l}\text { Porcentagem de gordura } \\
\text { Fatpercentage }\end{array}$ & $20,4 \pm 0,8$ & $20,4 \pm 0,6$ & $21,0 \pm 0,7$ & 0,7805 \\
\hline $\begin{array}{l}\text { Porcentagem de osso } \\
\text { Bone percentage }\end{array}$ & $19,6 \pm 0,4$ & $19,8 \pm 0,3$ & $19,5 \pm 0,4$ & 0,8137 \\
\hline $\begin{array}{l}\text { Músculo/osso } \\
\text { Muscle/bone }\end{array}$ & $3,29 \pm 0,07$ & $3,25 \pm 0,06$ & $3,28 \pm 0,06$ & 0,6600 \\
\hline $\begin{array}{l}\text { Músculo + gordura/osso } \\
\text { Muscle + fat/bone }\end{array}$ & $4,35 \pm 10,10$ & $4,29 \pm 0,09$ & $4,37 \pm 0,10$ & 0,8580 \\
\hline
\end{tabular}
concentrate levels 
mação de carcaça quando se elevou o nível de energia da dieta, sendo de 9,$05 ; 9,67$ e 9,82 pontos, respectivamente, nos níveis de concentrado $0 ; 0,3$ e $0,9 \%$ do peso vivo.

Berg \& Butterfield (1976) relataram que, apesar de ser esperado maior crescimento muscular, e portanto melhor conformação de carcaça, a melhoria do nível energético da dieta se expressa de forma mais evidente na deposição de gordura da carcaça.

No presente trabalho, constatou-se que a percentagem de gordura na carcaça não diferiu entre os tratamentos $(\mathrm{P}>0,05)$, comportamento também verificado para as percentagens de músculo e osso na carcaça. Signoretti et al. (1999), ao trabalharem com dois pesos de abate, verificaram que, no grupo de novilhos abatidos com maior peso, o nível de concentrado usado durante a terminação não alterou o teor de gordura da carcaça, como ocorreu quando o peso de abate foi mais baixo. Em fêmeas, Lanna et al. (1999) observaram que o teor de extrato etéreo na carcaça foi levemente maior nos animais alimentados com maiores níveis de concentrado na dieta.

Assim como as percentagens de músculo e osso, as relações músculo/osso e músculo + gordura/osso foram similares entre os níveis de concentrado estudados $(\mathrm{P}>0,05)$, o que representa um bom indicativo para a qualidade dos volumosos utilizados. Estudando a composição física da carcaça de animais F1 Limousin x Nelore, Gesualdi Júnior et al. (2000) verificaram que somente a percentagem de ossos foi afetada pelo nível de concentrado, decrescendo linearmente à medida que melhorou o nível de concentrado oferecido aos animais.

A cor da carne foi similar entre os níveis de concentrado oferecidos aos animais (Tabela 4). Arthaud et al. (1977) verificaram carne de coloração semelhante entre novilhos jovens terminados com níveis energéticos como alto ou baixo na dieta.

Tabela 4 - Médias e desvios-padrão para características de qualidade da carne de novilhos alimentados com diferentes níveis de concentrado

Table 4 - Means and standard deviations for meat quality characteristics of steers fed different concentrate lelvels

\begin{tabular}{|c|c|c|c|c|}
\hline \multirow[t]{2}{*}{$\begin{array}{l}\text { Características } \\
\text { Characteristics }\end{array}$} & \multicolumn{3}{|c|}{$\begin{array}{c}\text { Nível de concentrado, \% } \\
\text { Concentrate level, \% }\end{array}$} & \multirow[t]{2}{*}{$\begin{array}{c}\text { Probabilidade } \\
\text { Probability }\end{array}$} \\
\hline & 25 & 35 & 45 & \\
\hline $\begin{array}{l}\text { Cor, pontos }{ }^{1} \\
\text { Meat color, points }\end{array}$ & $3,72 \pm 0,20$ & $3,67 \pm 0,17$ & $3,83 \pm 0,18$ & 0,7965 \\
\hline $\begin{array}{l}\text { Textura, pontos } \\
\text { Meat texture, points } \\
{ }^{2}\end{array}$ & $3,79 \pm 0,17$ & $3,85 \pm 0,15$ & $3,67 \pm 0,15$ & 0,6706 \\
\hline $\begin{array}{l}\text { Marmoreio, pontos }{ }^{3} \\
\text { Marbling score, points }\end{array}$ & $3,68 \pm 0,42$ & $4,37 \pm 0,37$ & $4,71 \pm 0,38$ & 0,1968 \\
\hline $\begin{array}{l}\text { Força de cizalhamento, } \mathrm{kg} \\
\text { Shear force, } \mathrm{kg}\end{array}$ & $7,18 \pm 0,45$ & $6,98 \pm 0,39$ & $6,34 \pm 0,40$ & 0,3289 \\
\hline $\begin{array}{l}\text { Maciez, pontos } 4 \\
\text { Meat tenderness, points }{ }^{4}\end{array}$ & $5,40 \pm 0,16 b^{5}$ & $5,71 \pm 0,26 b$ & $6,42 \pm 0,23 a$ & 0,0146 \\
\hline $\begin{array}{l}\text { Palatabilidade, pontos } 4 \\
\text { Flavor, points } 4\end{array}$ & $6,31 \pm 0,19$ & $5,95 \pm 0,16$ & $5,91 \pm 0,17$ & 0,2377 \\
\hline $\begin{array}{l}\text { Suculência, pontos } 4 \\
\text { Juiciness, points }{ }^{4}\end{array}$ & $5,78 \pm 0,16$ & $5,76 \pm 0,14$ & $5,83 \pm 0,14$ & 0,9338 \\
\hline $\begin{array}{l}\text { Quebra ao descongelar, } \% \\
\text { Thawing loss, } \%\end{array}$ & $7,29 \pm 0,72$ & $7,64 \pm 0,62$ & $7,70 \pm 0,64$ & 0,9039 \\
\hline $\begin{array}{l}\text { Quebra ao cozinhar, \% } \\
\text { Cooking loss, \% }\end{array}$ & $27,4 \pm 1,0 \mathrm{ab}$ & $26,9 \pm 0,9 b$ & $29,6 \pm 0,9 a$ & 0,0466 \\
\hline $\begin{array}{l}1 \text { Escala de } 1 \text { a } 5 \text { pontos, send } \\
1 \text { Score from } 1 \text { to } 5 \text { points, being } 3 \\
2 \text { Escala de } 1 \text { a } 5 \text { pontos, seno } \\
2 \text { Score from } 1 \text { to } 5 \text { points, being } 2 \\
{ }^{3} \text { Escala de } 1 \text { a } 18 \text { pontos, sen } \\
{ }^{3} \text { Score from } 1 \text { to } 18 \text { points, being } \\
4 \text { Escala de } 1 \text { a } 9 \text { pontos, sendc } \\
\text { macia, extremamente sucule } \\
{ }^{4} \text { Score from } 1 \text { to } 9 \text { points, being } 1 \\
5 \text { a, b na linha, são diferentes } \\
5 \text { a, b in the line, are different by } t\end{array}$ & $\begin{array}{l}=\text { vermelha lever } \\
\text { ht dark red and } 4 \\
=\text { grosseira, } 3= \\
\text { rrse, } 3=\text { slightly } \\
=\text { leve menos, } 5 \\
\text { ght minus, } 5=\text { slig } \\
\text { extremamente d } \\
\text { extremamente } \\
\text { emely tough, dry, }\end{array}$ & $\begin{array}{l}\text { nte escura e } 4 \\
\text { red. } \\
\text { vemente gross } \\
\text { rse and } 4=\text { fine. } \\
\text { leve e } 6=\text { lev } \\
\text { and } 6=\text { slight pl } \\
\text { a, sem suculêr } \\
\text { borosa. } \\
\text { desirable and } 9\end{array}$ & $\begin{array}{l}\text { vermelha. } \\
\text { ra e } 4 \text { = fina. } \\
\text { mais. } \\
\text { a e sem sabor } \\
\text { xtremely tender }\end{array}$ & $\begin{array}{l}\text { extremamente } \\
\text { and flavorful. }\end{array}$ \\
\hline
\end{tabular}


A textura da carne foi similar entre os três tratamentos ( $P>0,05)$, sendo classificada como fina.

A maciez foi melhor no nível mais alto de concentrado que em 25 e 35\%, resultado que Di Marco (1998) associa à maior deposição de gordura intermuscular, e, portanto, maior facilidade de rompimento dos sarcômeros e das fibras da carne. O marmoreio foi similar entre os três níveis de concentrado, embora, numericamente, esta característica tenha melhorado nos níveis mais altos de concentrado oferecidos para os animais, o que poderia ocasionar diferença significativa entre os tratamentos se o período de terminação fosse mais prolongado (Berg \& Butterfield, 1976; Feijó et al., 1996). Entretanto, Marshall (1994) acredita que a alimentação pré-desmame tem grande efeito sobre a quantidade de marmoreio presente na carne e, por isso, durante a terminação, estaria melhor correlacionada com a deposição de gordura subcutânea. Outro fator importante é a qualidade dos dois tipos de silagens utilizados, pois a associação de níveis baixos de concentrado com volumosos de pior qualidade poderia resultar em animais com carne mais magra.

Constam, na Tabela 5, os resultados referentes a características da carcaça dos novilhos, em função do tipo de silagem de sorgo usado como fonte de volumoso. O tipo de silagem de sorgo não promoveu diferenças para a conformação de carcaça. Mesmo usando volumosos mais díspares em qualidade, Vaz \& Restle (2004) observaram valores similares para conformação de carcaça dos novilhos, com 9,33 pontos nos animais alimentados com cana-de-açúcar e 9,67 pontos naqueles que consumiram silagem de milho.Como na comparação entre os níveis de concentrado, não foi observada diferença significativa entre os tipos de volumosos utilizados para os resultados relativos à composição física da carcaça e relações músculo/ osso e músculo + gordura/osso.

Os resultados referentes ao efeito do tipo de híbrido de sorgo utilizado na confecção da silagem sobre as características cor, textura, marmoreio, características sensitivas da carne e quebras durante o preparo encontram-se na Tabela 6. Os novilhos alimentados com silagem de sorgo duplo propósito apresentaram carne de melhor coloração $(\mathrm{P}<0,05)$ que os alimentados com silagem de sorgo forrageiro. Müller et al. (1990) testaram a terminação em pastagem cultivada ou na associação entre pastagem nativa e cultivada e observaram melhor coloração da carne nos animais melhor alimentados, ou seja, terminados exclusivamente em pastagem cultivada.

Assim como verificado para o efeito dos níveis de concentrado, a textura e o marmoreio da carne não diferiram com o tipo de silagem utilizado sendo que ambos grupos de novilhos apresentaram carne com textura "fina" e marmoreio "leve menos". Testando

Tabela 5 - Médias e desvios-padrão para características da carcaça de novilhos alimentados com silagem de dois híbridos de sorgo

Table 5 - Means and standard deviations for carcass characteristics of steers fed two sorghum hybrids silage

\begin{tabular}{|c|c|c|c|}
\hline \multirow[t]{2}{*}{$\begin{array}{l}\text { Características } \\
\text { Characteristics }\end{array}$} & \multicolumn{2}{|c|}{$\begin{array}{l}\text { Silagem de sorgo } \\
\text { Sorghum silage }\end{array}$} & \multirow[t]{2}{*}{$\begin{array}{c}\text { Probabilidade } \\
\text { Probability }\end{array}$} \\
\hline & $\begin{array}{c}\text { Forrageiro } \\
\text { Forage }\end{array}$ & $\begin{array}{l}\text { Duplo propósito } \\
\text { Double purpose }\end{array}$ & \\
\hline $\begin{array}{l}\text { Conformação, pontos } 1 \\
\text { Conformation, points }\end{array}$ & $9,83 \pm 0,30$ & $10,32 \pm 0,28$ & 0,2390 \\
\hline $\begin{array}{l}\text { Porcentagem de músculo } \\
\text { Muscle percentage }\end{array}$ & $63,6 \pm 0,5$ & $64,1 \pm 0,5$ & 0,4011 \\
\hline $\begin{array}{l}\text { Porcentagem de gordura } \\
\text { Fatpercentage }\end{array}$ & $21,3 \pm 0,6$ & $20,0 \pm 0,6$ & 0,1161 \\
\hline $\begin{array}{l}\text { Porcentagem de osso } \\
\text { Bone percentage }\end{array}$ & $19,2 \pm 0,3$ & $20,0 \pm 0,3$ & 0,0706 \\
\hline $\begin{array}{l}\text { Músculo/osso } \\
\text { Muscle/bone }\end{array}$ & $3,32 \pm 0,05$ & $3,23 \pm 0,05$ & 0,2333 \\
\hline $\begin{array}{l}\text { Músculo + gordura/osso } \\
\text { Muscle + fat/bone }\end{array}$ & $4,43 \pm 0,08$ & $4,24 \pm 0,08$ & 0,1076 \\
\hline
\end{tabular}


Tabela 6 - Médias e desvios-padrão para características de qualidade da carne de novilhos alimentados com silagem de dois híbridos de sorgo

Table 6 - Means and standard deviations for meat quality characteristics of steers fed two sorghum hybrids silage

\begin{tabular}{|c|c|c|c|}
\hline \multirow[t]{2}{*}{$\begin{array}{l}\text { Características } \\
\text { Characteristics }\end{array}$} & \multicolumn{2}{|c|}{$\begin{array}{l}\text { Silagem de sorgo } \\
\text { Sorghum silage }\end{array}$} & \multirow[t]{2}{*}{$\begin{array}{c}\text { Probabilidade } \\
\text { Probability }\end{array}$} \\
\hline & $\begin{array}{c}\text { Forrageiro } \\
\text { Forage }\end{array}$ & $\begin{array}{l}\text { Duplo propósito } \\
\text { Double purpose }\end{array}$ & \\
\hline $\begin{array}{l}\text { Cor, pontos }{ }^{1} \\
\text { Meat color, points }\end{array}$ & $3,49 \pm 0,15$ & $4,00 \pm 0,15$ & 0,0211 \\
\hline $\begin{array}{l}\text { Textura, pontos } \\
\text { Meat texture, points } \\
\end{array}$ & $3,67 \pm 0,13$ & $3,87 \pm 0,12$ & 0,2912 \\
\hline $\begin{array}{l}\text { Marmoreio, pontos }{ }^{3} \\
\text { Marbling score, points }\end{array}$ & $4,11 \pm 0,33$ & $4,40 \pm 0,31$ & 0,5233 \\
\hline $\begin{array}{l}\text { Força de cizalhamento, } \mathrm{kg} \\
\text { Shear force, } \mathrm{kg}\end{array}$ & $6,94 \pm 0,34$ & $6,72 \pm 0,33$ & 0,6542 \\
\hline $\begin{array}{l}\text { Maciez, pontos } \\
\text { Meat tenderness, points }\end{array}$ & $5,62 \pm 0,20$ & $6,06 \pm 0,19$ & 0,6234 \\
\hline $\begin{array}{l}\text { Palatabilidade, pontos } 4 \\
\text { Flavor, points } 4\end{array}$ & $6,37 \pm 0,14$ & $5,74 \pm 0,14$ & 0,0033 \\
\hline $\begin{array}{l}\text { Suculência, pontos }{ }^{4} \\
\text { Juiciness, points }{ }^{4}\end{array}$ & $5,95 \pm 0,12$ & $5,63 \pm 0,12$ & 0,0664 \\
\hline $\begin{array}{l}\text { Quebra ao descongelar, \% } \\
\text { Thawing loss, } \%\end{array}$ & $7,34 \pm 0,56$ & $7,75 \pm 0,53$ & 0,5997 \\
\hline $\begin{array}{l}\text { Quebra ao cozinhar, \% } \\
\text { Cooking loss, } \% \\
\end{array}$ & $26,7 \pm 0,8 \mathrm{a}$ & $29,2 \pm 0,8 b$ & 0,0334 \\
\hline \multicolumn{4}{|c|}{$\begin{array}{l}1 \text { Escala de } 1 \text { a } 5 \text { pontos, sendo } 3=\text { vermelha levemente escura e } 4 \text { = vermelha. } \\
1 \text { Score from } 1 \text { to } 5 \text { points, being } 3=\text { slight dark red and } 4=\text { red. } \\
2 \text { Escala de } 1 \text { a } 5 \text { pontos, sendo } 2=\text { grosseira, } 3=\text { levemente grosseira e } 4 \text { = fina. } \\
2 \text { Score from } 1 \text { to } 5 \text { points, being } 2=\text { coarse, } 3=\text { slightly coarse and } 4=\text { fine. } \\
3 \text { Escala de } 1 \text { a } 18 \text { pontos, sendo } 4=\text { leve menos, } 5=\text { leve e } 6=\text { leve mais. } \\
3 \text { Score from } 1 \text { to } 18 \text { points, being } 4=\text { slight minus, } 5=\text { slight and } 6=\text { slight plus. } \\
4 \text { Escala de } 1 \text { a } 9 \text { pontos, sendo } 1=\text { extremamente dura, sem suculência e sem sabor, e } 9=\text { extremamente } \\
\text { macia, extremamente suculenta e extremamente saborosa. } \\
{ }^{4} \text { Score from } 1 \text { to } 9 \text { points, being } 1=\text { extremly tough, dry, undesirable and } 9=\text { extremly tender, juicy and flavorful. }\end{array}$} \\
\hline
\end{tabular}

dois volumosos, Vaz \& Restle (2004) observaram similaridade na textura e no marmoreio da carne entre os tratamentos, embora estas características tenham sido classificadas como "fina" e "leve mais", respectivamente, nos animais terminados com cana-de-açúcar, e como "muito fina" e "pequeno menos" naqueles terminados com silagem de milho. Vaz et al. (2003) verificaram textura entre "média"e "fina" e marmoreio "leve menos", em búfalos alimentados com cana-deaçúcar, e textura "fina" e marmoreio "traços mais" nos búfalos tratados com silagem de milho.

A força de cizalhamento e a maciez da carne medidas pelo painel de degustadores foram similares entre os dois grupos de novilhos, ao passo que a palatabilidade da carne foi melhor $(\mathrm{P}<0,05)$ nos novilhos alimentados com silagem de sorgo forrageiro. Os mecanismos associados à palatabilidade da carne são bastante subjetivos e variam entre consumidores, porém, espera-se que animais alimentados com me- nores teores de fibra apresentem carne com melhor palatabilidade (Müller, 1987).

A suculência da carne foi similar entre os tratamentos $(\mathrm{P}>0,05)$, assim como a quebra durante o descongelamento. Todavia, a quebra durante a cocção foi maior $(29,2 \%)$ nos novilhos alimentados com silagem de sorgo duplo propósito que nos alimentados com sorgo forrageiro (26,7\%). Vaz \& Restle (2004) registraram valores similares para quebra durante a cocção da carne, mas observaram maior quebra ao descongelamento na carne de novilhos terminados com cana-de-açúcar $(6,10 \%)$ que na carne de animais tratados com silagem de milho $(3,69 \%)$, comportamento também reportado por $\mathrm{Vaz}$ et al. (2003) para carne de bubalinos terminados com canade-açúcar $(5,83 \%)$ ou silagem de milho $(4,80 \%)$.

A conformação de carcaça foi classificada como boa típica ( 10,8 pontos) nos novilhos com predominância de Charolês e como regular mais ( 9,35 pontos) nos 


\begin{tabular}{|c|c|c|c|}
\hline \multirow[t]{2}{*}{$\begin{array}{l}\text { Características } \\
\text { Characteristics }\end{array}$} & \multicolumn{2}{|c|}{$\begin{array}{l}\text { Grupo genético } \\
\text { Genetic group }\end{array}$} & \multirow[t]{2}{*}{$\begin{array}{c}\text { Probabilidade } \\
\text { Probability }\end{array}$} \\
\hline & $\begin{array}{c}\text { Predominância de Charolês } \\
\text { Charolais predominance }\end{array}$ & $\begin{array}{c}\text { Predominância de Nelore } \\
\text { Nellore predominance }\end{array}$ & \\
\hline $\begin{array}{l}\text { Conformação, pontos } 1 \\
\text { Conformation, points } 1\end{array}$ & $10,81 \pm 0,27$ & $9,35 \pm 0,31$ & 0,0009 \\
\hline $\begin{array}{l}\text { Porcentagem de músculo } \\
\text { Muscle percentage }\end{array}$ & $65,8 \pm 0,4$ & $61,9 \pm 0,5$ & 0,0001 \\
\hline $\begin{array}{l}\text { Porcentagem de gordura } \\
\text { Fatpercentage }\end{array}$ & $18,9 \pm 0,5$ & $22,3 \pm 0,6$ & 0,0001 \\
\hline $\begin{array}{l}\text { Porcentagem de osso } \\
\text { Bone percentage }\end{array}$ & $19,5 \pm 0,3$ & $19,8 \pm 0,3$ & 0,5402 \\
\hline $\begin{array}{l}\text { Músculo/osso } \\
\text { Muscle/bone }\end{array}$ & $3,40 \pm 0,05$ & $3,15 \pm 0,06$ & 0,0018 \\
\hline $\begin{array}{l}\text { Músculo + gordura/osso } \\
\text { Muscle }+ \text { fat/bone }\end{array}$ & $4,38 \pm 0,08$ & $4,30 \pm 0,09$ & 0,4839 \\
\hline
\end{tabular}

novilhos com predominância de Nelore (Tabela 7). Melhor conformação na carcaça de animais Charolês em relação aos Nelore foi descrita por Perobelli et al. (1994), que atribuíram este fato à maior aptidão para produção de carne do genótipo europeu.

O genótipo com predominância de Nelore apresentou maior percentual de gordura na carcaça em detrimento à percentagem de músculo, que foi maior nos predominantemente Charolês, assim como a relação músculo/osso $(3,40 \pm 0,05$ vs $3,15 \pm 0,06)$. Não houve diferença significativa entre os genótipos para percentagem de osso e relação músculo + gordura/ osso. Luchiari Filho (1989) observaram valores similares para a porcentagem de osso na carcaça de bovinos Canchim e Nelore, enquanto Restle et al. (2003) registraram maior percentagem de gordura na carcaça de vacas mestiças Nelore x Charolês $(28,1 \%)$ que nas Charolês definidas $(20,1)$, diferença que refletiu na relação músculo + gordura/osso, que também foi maior nas vacas mestiças Nelore x Charolês $(6,52$ vs 5,56$)$.

Moletta \& Restle (1996) verificaram maior percentagem de gordura em animais Nelore que nos Charolês. Vaz (1999) justificou a maior musculosidade da carcaça de animais Charolês como característica das raças continentais, que foram selecionadas para características de crescimento, ao contrário das raças britânicas, que são mais precoces, e das raças indianas, que apresentam características de rusticidade.
Na Tabela 8, são apresentados os resultados referentes ao efeito do grupo genético sobre as características cor, textura, marmoreio, características sensitivas da carne e quebras durante o preparo. A coloração da carne e a textura foram similares $(\mathrm{P}>0,05)$ entre os grupos genéticos estudados.

O marmoreio foi maior nos novilhos com predominância do genótipo Charolês que nos predominantemente Nelore. Marshall (1994) verificaram 10,3 e 9,3 pontos para o marmoreio de novilhos Charolês e Brahman, respectivamente. No mesmo trabalho, o autor relata que o aumento da participação de genótipo Bos taurus indicus reduz a marmorização da carne e piora a maciez, medida pelo painel de degustadores, e a força de cizalhamento, medida pelo WB-Shear. No presente trabalho, a maciez da carne foi menor nos animais com predominância de Nelore, que apresentaram, também, carne com maiores valores de cizalhamento $(\mathrm{P}<0,05)$.

Wheeler et al. (1994) buscaram estabelecer o efeito do grau de marmoreio sobre a maciez e força de cizalhamento na carne de genótipos Bos taurus indicus e Bos taurus taurus, observando que nos zebuínos o aumento do grau de marmoreio é mais importante para melhorar a maciez da carne e diminuir a força de cizalhamento, que nos genótipos europeus. Resultados similares foram verificados por Vaz (1999), que, ao estudar novilhos Charolês e Nelore, verificou que nos Charolês a correlação entre marmoreio e maciez foi de 0,11 e nos Nelore de 0,19. 
Tabela 8 - Médias e desvios-padrão para características de qualidade da carne de novilhos de dois grupos genéticos

Table 8 - Means and standard deviations for meat quality characteristics of steers of two genetic groups

\begin{tabular}{|c|c|c|c|}
\hline \multirow[t]{2}{*}{$\begin{array}{l}\text { Características } \\
\text { Characteristics }\end{array}$} & \multicolumn{2}{|c|}{$\begin{array}{l}\text { Grupo genético } \\
\text { Genetic group }\end{array}$} & \multirow[t]{2}{*}{$\begin{array}{l}\text { Probabilidade } \\
\text { Probability }\end{array}$} \\
\hline & $\begin{array}{c}\text { Predominância de Charolês } \\
\text { Charolais predominance }\end{array}$ & $\begin{array}{c}\text { Predominância de Nelore } \\
\text { Nellore predominance }\end{array}$ & \\
\hline $\begin{array}{l}\text { Cor, pontos }{ }^{1} \\
\text { Meat color, points }\end{array}$ & $3,94 \pm 0,14$ & $3,55 \pm 0,16$ & 0,0763 \\
\hline $\begin{array}{l}\text { Textura, pontos }{ }^{2} \\
\text { Meat texture, points }\end{array}$ & $3,94 \pm 0,12$ & $3,60 \pm 0,14$ & 0,0703 \\
\hline $\begin{array}{l}\text { Marmoreio, pontos }{ }^{3} \\
\text { Marbling score, points }\end{array}$ & $4,76 \pm 0,30$ & $3,77 \pm 0,34$ & 0,0291 \\
\hline $\begin{array}{l}\text { Força de cizalhamento, } \mathrm{kg} \\
\text { Shear force, } \mathrm{kg}\end{array}$ & $5,87 \pm 0,32$ & $7,80 \pm 0,36$ & 0,0002 \\
\hline $\begin{array}{l}\text { Maciez, pontos } \\
\text { Meat tenderness, points }\end{array}$ & $6,43 \pm 0,18$ & $5,26 \pm 0,21$ & 0,0001 \\
\hline $\begin{array}{l}\text { Palatabilidade, pontos } 4 \\
\text { Flavor, points } 4\end{array}$ & $6,17 \pm 0,13$ & $5,94 \pm 0,15$ & 0,2379 \\
\hline $\begin{array}{l}\text { Suculência, pontos } 4 \\
\text { Juiciness, points } 4\end{array}$ & $5,99 \pm 0,11$ & $5,60 \pm 0,13$ & 0,0270 \\
\hline $\begin{array}{l}\text { Quebra ao descongelar, } \% \\
\text { Thawing loss, } \%\end{array}$ & $6,40 \pm 0,51$ & $8,69 \pm 0,58$ & 0,0046 \\
\hline $\begin{array}{l}\text { Quebra ao cozinhar, \% } \\
\text { Cooking loss, } \%\end{array}$ & $27,5 \pm 0,7$ & $28,5 \pm 0,8$ & 0,3718 \\
\hline \multicolumn{4}{|c|}{$\begin{array}{l}1 \text { Escala de } 1 \text { a } 5 \text { pontos, sendo } 3=\text { vermelha levemente escura e } 4=\text { vermelha. } \\
1 \text { Score from } 1 \text { to } 5 \text { points, being } 3=\text { slight dark red and } 4=\text { red. } \\
2 \text { Escala de } 1 \text { a } 5 \text { pontos, sendo } 2=\text { grosseira, } 3=\text { levemente grosseira e } 4 \text { = fina. } \\
2 \text { Score from } 1 \text { to } 5 \text { points, being } 2=\text { coarse, } 3=\text { slightly coarse and } 4=\text { fine. } \\
{ }^{3} \text { Escala de } 1 \text { a } 18 \text { pontos, sendo } 4=\text { leve menos, } 5=\text { leve e } 6=\text { leve mais. } \\
{ }^{3} \text { Score from } 1 \text { to } 18 \text { points, being } 4=\text { slight minus, } 5=\text { slight and } 6=\text { slight plus. } \\
{ }^{4} \text { Escala de } 1 \text { a } 9 \text { pontos, sendo } 1=\text { extremamente dura, sem suculência e sem sabor, e } 9=\text { extremamente macia, } \\
\text { extremamente suculenta e extremamente saborosa. } \\
{ }^{4} \text { Score from } 1 \text { to } 9 \text { points, being } 1=\text { extremely tough, dry, undesirable and } 9=\text { extremly tender, juicy and flavorful. }\end{array}$} \\
\hline
\end{tabular}

Com relação à palatabilidade, houve similaridade entre os dois grupos de novilhos $(\mathrm{P}>0,05)$, assim como a quebra durante a cocção, que foi de $27,5 \pm 0,7 \%$ no

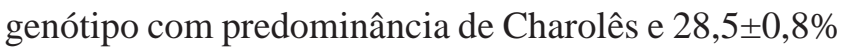
no genótipo predominantemente Nelore. Entretanto, nos novilhos Nelores observou-se maior quebra da carne durante o descongelamento $(8,69 \pm 0,58$ vs $6,40 \pm 0,51 \%)$, o que pode ter sido determinante de uma carne com menor suculência nos zebuínos $(5,60 \pm 0,13$ pontos $)$ em relação aos europeus $(5,99 \pm 0,11$ pontos) (Tabela 8$)$.

Wheeler et al. (1994) acreditam que, ao contrário do que acontece com a maciez, a variação na suculência da carne é mais afetada pelo grau de marmoreio da carne em genótipos Bos taurus taurus que em genótipos Bos taurus indicus, porém esses efeitos genéticos não são claros quando é considerada a palatabilidade da carne. Em novilhos abatidos aos dois anos, Vaz (1999) observou coeficientes de correlação fenotípica entre marmoreio e palatabilidade de 0,19 em novilhos Charolês, valor que passa para 0,24 quando é calculada para novilhos Nelore.

\section{Conclusões}

O aumento do nível de concentrado da dieta durante a terminação de novilhos melhora a conformação de carcaça e maciez da carne.

Novilhos alimentados com silagem de sorgo forrageiro apresentam carne com melhor palatabilidade que os alimentados com silagem de sorgo duplo propósito.

Novilhos com predominância de Charolês no genótipo apresentam melhor conformação de carcaça, maior percentagem de músculo e maior relação músculo/osso. Carcaças de novilhos com predominância de Nelore no genótipo possuem maior percentual de gordura que carcaças de novilhos com predominância de Charolês.

A carne de animais com predominância de Charolês no genótipo apresenta maior quantidade de marmoreio, é mais macia e suculenta que a de novilhos com predominância de Nelore no genótipo. 


\section{Literatura Citada}

ARTHAUD, V.H.; MANDIGO, R.W.; KOCH, R.M. et al. Carcass composition, quality and palatability attributes of bulls and steers feed different energy levels and killed at four ages. Journal of Animal Science, v.44, n.1, p.53-64, 1977.

BERG, R.T.; BUTTERFIELD, R.M. New concepts of cattle growth. Sydney: Sydney University Press, 1976. 240p.

DI MARCO, O.N. Crecimiento de vacunos para carne. Balcarce: AAPA, 1998. 246p.

FEIJÓ, G.L.D.; THIAGO, L.R.L.S.; ARRUDA, E.F. Efeito de níveis de concentrado na engorda de bovinos confinados. Características das carcaças de animais Nelore. In: REUNIÃO ANUAL DA SOCIEDADE BRASILEIRA DE ZOOTECNIA, 33., 1996, Fortaleza. Anais... Fortaleza: Sociedade Brasileira de Zootecnia, 1996, p.76-78.

GESUALDI JR., A.; PAULINO, M.F.; VALADARES FILHO, S.C. Níveis de concentrado na dieta de novilhos F1 Limousin $x$ Nelore: características de carcaça. Revista Brasileira de Zootecnia, v.29, n.5, p.1467-1473, 2000.

HANKINS, O.G.; HOWE, P.E. Estimation of the composition of beef carcasses and cuts. Washington: United States Department of Agriculture, 1946 (Technical Bulletin, n.926).

LANNA, D.P.D.; MORAIS, J.P.; BOIN, C. et al. Desempenho e composição corporal de novilhas alimentadas com dois níveis de concentrado e bagaço de cana submetido a diferentes processos de hidrólise. Revista Brasileira de Zootecnia, v.28, n.2, p.412-420, 1999.

LUCHIARI FILHO, A.; LEME, P.R.; RAZOOK, A.G. et al. Características de carcaça e rendimento da porção comestível de machos Nelore comparados a cruzados (F1) obtidos do acasalamento de touros das raças Canchim, Santa Gertrudis, Caracu, Holandês e Suíço com fêmeas Nelore. II Animais castrados terminados a pasto. Boletim da Indústria Animal, v.46, n.1, p.27-35, 1989.

MARSHALL, D.M. Breed differences and genetic parameters for body composition traits in beef cattle. Journal of Animal Science, v.72, n.10, p.2745-2755, 1994.

MOLETTA, J.L.; RESTLE, J. Influência do grupo genético sobre características qualitativas da carne de novilhos. Revista da Sociedade Brasileira de Zootecnia, v.26, n.5, p.866-875, 1996.

MÜLLER, L.; AGUIRRE, L.F.; RESTLE, J. et al. Parâmetros qualitativos da carne de bovinos submetidos a dois regimes alimentares durante o inverno. In: REUNIÃO ANUAL DA SOCIEDADE BRASILEIRA DE ZOOTECNIA, 27., 1990, Campinas. Anais... Campinas: Sociedade Brasileira de Zootecnia, 1990. p.355.

MÜLLER, L. Normas para avaliação de carcaças e concurso de carcaça de novilhos. 2.ed. Santa Maria: Universidade Federal de Santa Maria, 1987. 31p.

NEUMANN, M.; RESTLE, J.; ALVES FILHO, D.C. et al. Avaliação do valor nutritivo da planta e da silagem de diferentes híbridos de sorgo (Sorghum bicolor, L. Moench). Revista Brasileira de Zootecnia, v.31, n.1, p.293-301, 2002 (Suplemento).
PEROBELLI, Z.V.; MÜLLER, L.; RESTLE, J. Estudo da qualidade das carcaças e da carne de vacas de descarte de dois grupos genéticos. Ciência Rural, v.24, n.3, p.613-616, 1994.

RESTLE, J.; VAZ, F.N.; BERNARDES, R.A.L.C. et al. Características de carcaça e da carne de vacas de descarte de diferentes genótipos Charolês x Nelore, terminadas em confinamento. Ciência Rural, v.33, n.2, p.345-350, 2003.

RESTLE, J.; VAZ, F.N. Tendências de mercado e entraves tecnológicos para a cadeia produtiva da carne bovina. In: MELlO, N.A.; ASSMAN, T.S. (Eds.) Encontro de integração lavoura-pecuária no Sul do Brasil, Pato Branco: IAPAR/CEFET, 2002. p.167-188.

RESTLE, J.; VAZ, F.N. Eficiência na produção de bovinos de corte. In: REUNIÃO ANUAL DA SOCIEDADE BRASILEIRA DE ZOOTECNIA, 40., Santa Maria, 2003. Anais das Palestras... Santa Maria: Sociedade Brasileira de Zootecnia, 2003, CD ROM.

STATISTICAL ANALYSES SYSTEM - SAS. SAS language reference. version 6, Cary: 1990. 1042p.

SIGNORETTI, R.D.; ARAÚJO, G.G.L.; SILVA, J.F.C. et al. Composição física da carcaça de bezerros da raça Holandês alimentados com dietas contendo diferentes níveis de concentrado. Revista Brasileira de Zootecnia, v.28, n.4, p.883-888, 1999.

VAZ, F.N. Cruzamento alternado das raças Charolês e Nelore: características de carcaça e da carne de novilhos abatidos aos dois anos. Santa Maria: Universidade Federal de Santa Maria, 1999. 58p. Dissertação (Mestrado em Zootecnia) - Universidade Federal de Santa Maria, 1999.

VAZ, F.N.; RESTLE, J. Características de carcaça e da carne de novilhos Hereford terminados em confinamento com diferentes fontes de volumoso. Revista Brasileira de Zootecnia. No prelo. 2004.

VAZ, F.N.; RESTLE, J.; BRONDANI, I.L. et al. Estudo da carcaça e da carne de bubalinos Mediterrâneo terminados em confinamento com diferentes fontes de volumoso. Revista Brasileira de Zootecnia, v.32, n.2, p.393-404, 2003.

VAZ, F.N.; RESTLE, J.; BRONDANI, I.L. et al. Suplementação energética sobre a qualidade da carcaça e da carne de vacas de diferentes idades, terminadas em pastagem cultivada de estação fria sob pastejo horário. Revista Brasileira de Zootecnia, v.31, n.1, p.173-182, 2002.

WHEELER, T.L.; CUNDIFF, L.V.; KOCH, R.M. Effect of marbling degree on beef palatability in Bos taurus and Bos indicus cattle. Journal of Animal Science, v.72, n.12, p.3145-3151, 1994. 